\title{
GRANULOMATOUS PROSTATITIS MIMICKING PROSTATE CANCER ON MAGNETIC RESONANCE IMAGING: REPORT OF TWO CASES
}

\author{
Andreas G. Wibmer', Hebert A. Vargas' ${ }^{1}$, Hedvig Hricak 1,2
}

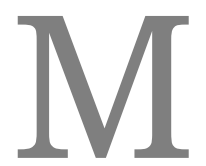

agnetic resonance imaging is a method of choice in the diagnosis of prostate cancer in case of primary cancer and to determine the staging. But MR-signs inherent in the classical for prostate cancer are not absolutely specific and can be caused by non-malignant pathological process, such as granulomatous prostatitis.

This paper presents two clinical cases of patients with histologically confirmed granulomatous prostatitis mimicking prostate cancer and reviewed published literature on this issue.

Keywords: granulomatous prostatitis, prostate cancer, MRI of the prostate.

1 - Memorial Sloan Kettering Cancer Center, Department of Radiology. New York, USA

2 - I.M. Sechenov First Moscow State Medical University (Sechenov University).

Corresponding author: Andreas G. Wibmer, e-mail: wibmera@mskcc.org Moscow, Russia.

For citation: Andreas G. Wibmer, Hebert Alberto Vargas, Hedvig Hricak. Granulomatous prostatitis mimicking prostate cancer on magnetic resonance imaging: report of two cases. REJR. 2017; 7 (2):153-157. DOI:10.21569/2222-7415-2017-7-2-153-157.

Received: 19.05.2017

Accepted: 05.06.2017

\section{МАГНИТНО-РЕЗОНАНСНАЯ ТОМОГРАФИЯ В АИАГНОСТИКЕ ГРАНУАЕМАТОЗНОГО ПРОСТАТИТА, ИМИТИРУЮЩЕГО РАК ПРЕАСТАТЕАЬНОЙ ЖЕАЕЗЫ: АВА САУЧАЯ ИЗ ПРАКТИКИ}

\author{
Андреас Г. Вибмер', Хеберт А. Варгас' , Хелвиг Кричак'1,2
}

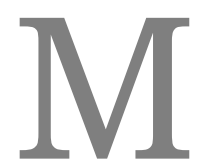

агнитно-резонансная томография давно стала методом выбора при диагно- 1 - Мемориальный стике рака простаты как на этапе первичного выявмения опухоли, так и на онкологический центр этапе определения стадирования. Но МР-признаки, присущие классическо- Слоана-Кеттеринга,

му течению рака предстательной железы не являются абсолютно специфичными, и мо- отдел мучевой диагногут быть вызваны незцокачественным патологическим процессом, таким как грануце- стики. Нью-Йорк, США. матозный простатит. 2 - ФГАОУ ВО Первый

В данной работе представлены два клинических примера магнитно-резонансной Московский томографии пациентов с гистологически подтвержденным гранулематозным простати- Медицинский том, имитирующим рак предстательной железы и рассмотрена опубликованная Аитера- Университет имени тура по данной пробцеме. И.М. Сеченова Минздрава России

КАючевые слова: гранулематозный простатит, рак предстательной железы, МРТ (Сеченовский предстательной жемезы. Университет) г. Москва, Россия.

Контактный автор: Andreas G. Wibmer, e-mail: wibmera@mskcc.org

Для иитирования: Andreas G. Wibmer, Hebert Alberto Vargas, Hedvig Hricak. Granulomatous prostatitis mimicking prostate cancer on magnetic resonance imaging: report of two cases. REJR. 2017; 7 (2):153-157. DOI:10.21569/2222-7415-2017-7-2-153-157. 
agnetic resonance imaging (MRI) of the prostate is the imaging modality of
choice for local staging of newly diagnosed prostate cancer $(\mathrm{PCa})$. It more precisely localizes a dominant tumor within the gland [1], and gives a more reliable estimation of tumor volume than digital rectal examination or transrectal ultrasound [2]. Most importantly, prostate MRI is more accurate for the diagnosis of extracapsular extension, seminal vesicle invasion, and involvement of adjacent organs [3-5], with direct implications on patient counseling, management, and therapy planing. For the reporting radiologist, it is essential to be familiar with prostate zonal anatomy and to recognize the typical imaging appearance of PCa. On T2-weighted images, tumors present as round or lenticular shaped masses that are homogeneously hypointense compared to the highsignal peripheral zone tissue. Diffusion-weighted imaging (DWI) reveals high signal intensity on lowand high-b-value images with hypointensity on the corresponding apparent diffusion coefficient

(ADC) maps. On dynamic contrast-enhanced (DCE) sequences, PCa typically demonstrates early enhancement compared to non-cancerous peripheral zone tissue. These characteristic findings may vary slightly depending on a lesion's zonal localization. Thus, in the most recent version of the Prostate Imaging Reporting and Data System (PI-RADS v2), assessment of peripheral zone lesions is primarily based upon DWI, whereas such in the transition zone are mainly assessed on T2weighted images. For a more detailed review of the PI-RADS scoring system, please refer to the original document [6] or recent pictorial reviews $[7,8]$.

While familiarity with the typical imaging appearance of $\mathrm{PCa}$ is essential for the reporting radiologist, it is as important to recognize that these findings are not perfectly specific for $\mathrm{PCa}$ and that there are non-cancerous mimics, as comprehensively reviewed in the recent literature $[9,10]$. We describe MR imaging findings of two patients with histopathology-proven granulomatous prostatitis (GP) mimicking PCa on MRI and review the pertinent literature.

Case 1.

A 69 year-old patient who was hospitalized in an outside institution for presumed urosepsis. A digital rectal examination showed a right-sided prostatic nodule extending from the base to the apex with suspicion for extracapsular extension. The serum prostate specific antigen (PSA) was 6.5 $\mathrm{ng} / \mathrm{ml}$. Transrectal ultrasound-guided 12-core biopsy was positive for high grade, low-volume $\mathrm{PCa}$ (Gleason score $4+4=8$ ), occupying $3 \%$ of one biopsy core. The biopsy also showed high-grade prostatic intraepithelial neoplasia (PIN) and signs of chronic inflammation. A prostate MRI showed a dominant lesion with the imaging features of $\mathrm{PCa}$ in the right posterolateral base-to-apex peripheral zone with extracapsular extension and possible invasion of the rectal wall (fig 1).

The patient's lower urinary tract symptoms resolved after a course of systemic antibiotics and he transferred his care to our institution, where he underwent radical retropubic prostatectomy. Whole-mount step-section histopathology showed two small foci of $\mathrm{PCa}$ (Gleason $3+4=7$ ) in the bilateral mid-gland peripheral zone as well as multifocal granulomatous prostatitis (fig 2).

Case 2.

53 year-old patient with a history of urothelial cancer of the bladder who had previously undergone multiple transurethral tumor resections of the bladder and two courses of intravesicular immunotherapy with Bacille Calmette-Guerin

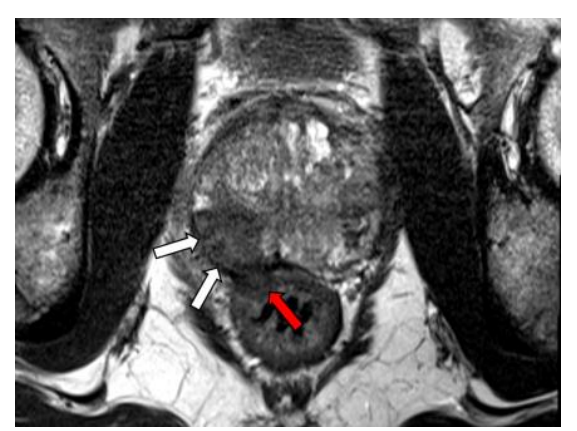

Fig. 1 a

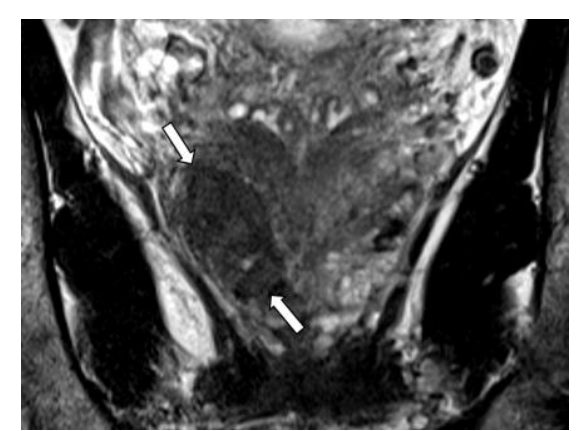

Fig. 1 b

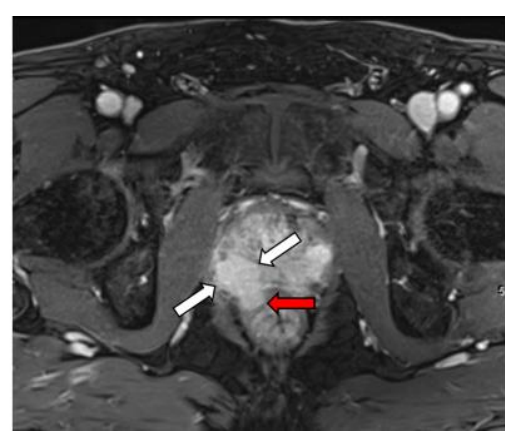

Fig. 1 c

Fig. 1. MRI. T2-WI.

Patient 1; T2-weighted MRI (a, b) of the prostate in the axial (a) and coronal (b) planes, and axial dynamic contrast enhanced image (c), showing a well defined lesion in the posterolateral base-to-apex peripheral zone (white arrows) with low signal intensity on T2-weighted and intense early enhancement on DCE images, respectively. The lesion extends into the posterior periprostatic soft tissue and possibly involves the anterior rectal wall (red arrows). The lesion was assigned a PI-RADS score of 5. 


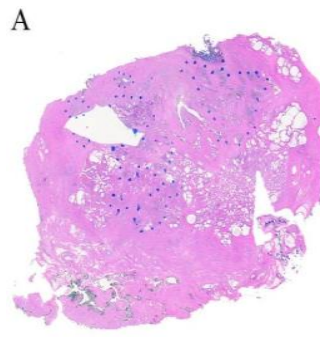

$\mathrm{R}$

$\mathrm{L}$
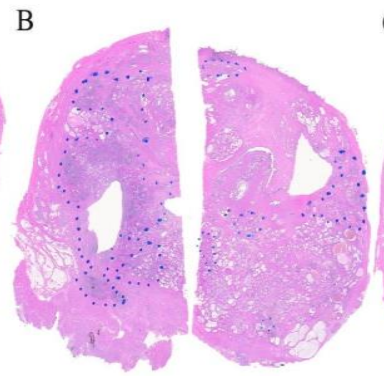

$\mathrm{C}$
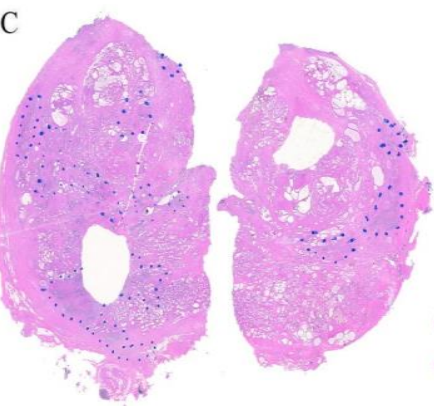
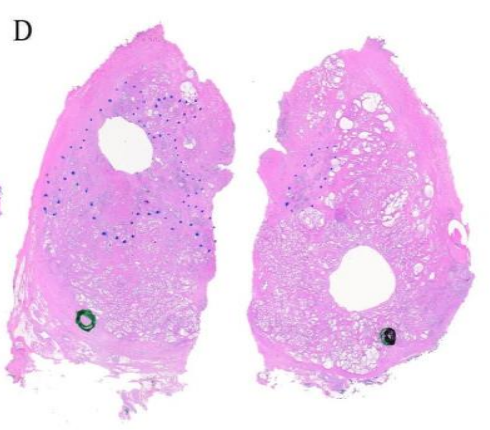

E

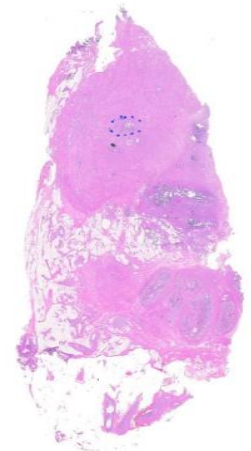

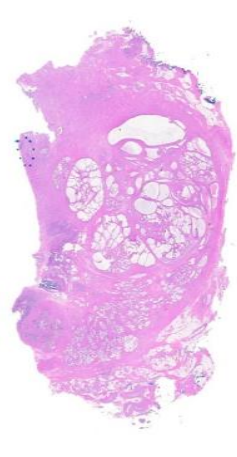

F

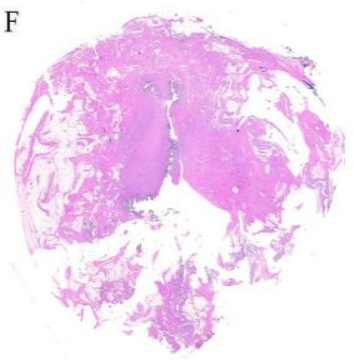

Fig. 2

Fig. 2. Patient 1; Whole-mount step-section histopathology of a prostatectomy specimen in the axial plane from the apex (a) through the base (f).There are two foci of prostate cancer in the bilateral mid-gland peripheral zone (both Gleason score 3+4=7), encircled by green/black lines on slice (d). Blue dotted lines on slices (a-e) indicate areas of granulomatous inflammation.

(BCG) at an outside institution. 18F-fluorodesoxyglucose PET/CT showed a focus of abnormal tracer uptake in the left side of the prostate (images not available), which was thought to possibly represent malignancy. The patient transferred his care to our institution in December 2016, which was 15 months after the end of the last BCG treatment. He had no lower urinary tract symptoms or fever. Serum PSA was 11.28 $\mathrm{ng} / \mathrm{ml}$ and digital rectal examination showed bilateral nodules without extracapsular extension. An MRI of the prostate showed multiple foci of homogeneously low signal on T2-weighted images and restricted diffusion, with the largest lesions at the prostate base (fig 3).

The patient underwent transrectal ultrasound-guided 14-core prostate biopsy, which showed no evidence of malignancy and multifocal necrotizing and non-necrotizing granulomatous inflammation. Special stains for acid-fast organisms were negative.

\section{Discussion.}

Granulomatous prostatitis is a rare inflammatory disease of the prostate with manifold etiologies, including, but not limited to, prior intravesicular BCG therapy for urothelial cancer, prior transurethral interventions, sarcoidosis, and infections, e.g. mycobacterial, parasitic, or cryptococcal. In a number of cases, no specific cause can be established and they are classified as idiopathic. It has to be emphasized that prior BCG therapy may be a major but not the only cause of GP in western societies, and that GP can present several months to years after BCG treatment, as seen in our case 2 and documented in prior reports $[11,12]$. GP shares many clinical and imaging characteristics with PCa, but management differs significantly, with most cases of GP resolving spontaneously or after therapy of an underlying infection. Patients typically present with lower urinary tract symptoms, fever, abnormal urine analysis (most commonly elevated white blood cells and/or hematuria), hematospermia, elevated serum PSA, and abnormal digital rectal examination, but any of these findings might also be absent. In a case series of 22 cases with histopathology-proven granulomatous prostatitis, Shukla and colleagues found that PSA-values ranged between 0.88 and $19.22 \mathrm{ng} / \mathrm{ml}$, and that 14 patients had a normal urine analysis [13]. In another series of 11 cases of GP, $45 \%$ had no abnormal findings on digital rectal examination [14].

On MRI, GP has similar imaging characteristics as PCa and it may be very difficult to distinguish these two entities based on their MRI appearance. Recently, Rais-Bahrami and colleagues from the University of Alabama compared the MRI and clinical findings of 5 patients with GP to 15 


\section{RUSSIAN ELECTRONIC JOURNAL OF RADIOLOGY}

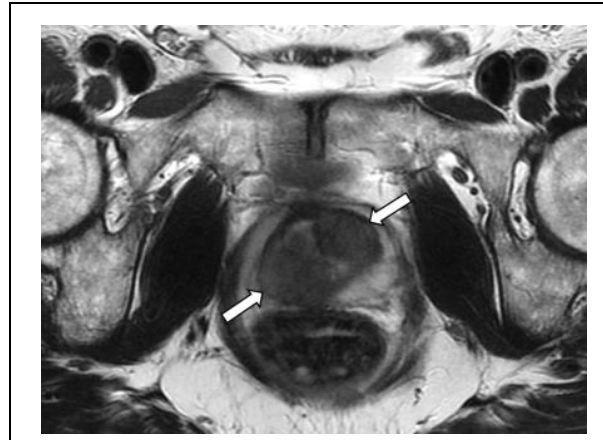

Fig. 3 a

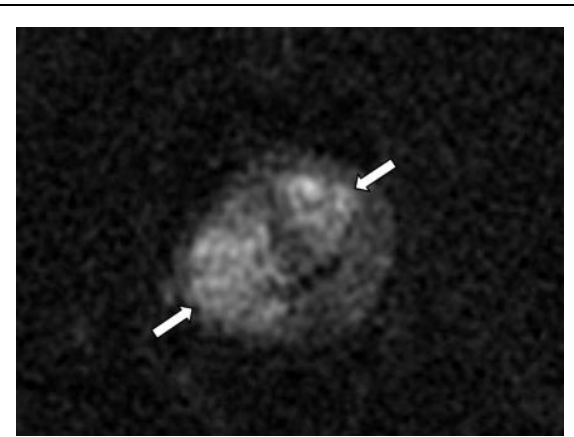

Fig. 3 b

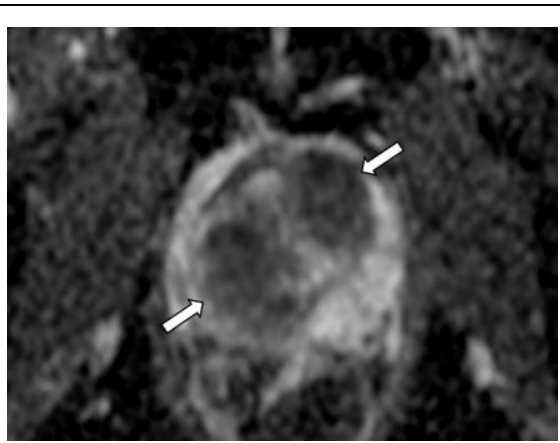

Fig. 3 c

\section{Fig. 3. MRI. T2-WI.}

Patient 2; T2-weighted MRI of the prostate in the axial plane (a), axial high b-value diffusion weighted image (b) and corresponding ADC map (c). There are two well defined lesions at the bilateral base peripheral / transition zone border with homogeneously low signal on T2-weighted images and restricted diffusion. The lesions were assigned PIRADS scores of 5.Transrectal ultrasound-guided 14-core biopsy was negative for malignancy and showed granulomatous inflammation in multiple cores.

matched patients with $\mathrm{PCa}$ [15]. While there was no difference in PSA-levels, lesion size, and distribution of PI-RADS scores between the two groups, they reported that the mean ADC was significantly higher in GP than in PCa (i.e. 1.05 vs. $0.79 \times 10-$ $3 \mathrm{~mm} 2 / \mathrm{s}, \mathrm{p}=0.002)$. In another series of $5 \mathrm{pa}$ tients, however, GP lesions showed markedly lower ADC mean values (i.e. $0.56 \times 10-3 \mathrm{~mm} 2 / \mathrm{s}$ ) [16]. None of Rais-Bahrami's patients with GP showed signs of extraprostatic diseases spread, while extracapsular extension was thought to be present in $33 \%$ of patients with PCa $(p=0.003)$ [15]. The latter observation is contrary to our case 1 and others who reported MRI findings that were suspicious for extraprostatic spread and/or involve-

\section{References:}

1. Mullerad M., Hricak H., Kuroiwa K., Pucar D., Chen H.N., Kattan M.W., et al. Comparison of endorectal magnetic resonance imaging, guided prostate biopsy and digital rectal examination in the preoperative anatomical localization of prostate cancer. The Journal of urology. 2005; 174 (6): 2158-63.

2. Sanchez-Chapado M., Angulo J.C., Ibarburen C., Aguado F., Ruiz A., Viano J., et al. Comparison of digital rectal examination, transrectal ultrasonography, and multicoil magnetic resonance imaging for preoperative evaluation of prostate cancer. European urology. 1997; 32 (2): 140-9.

3. Presti J.C., Jr., Hricak H., Narayan P.A., Shinohara K., White S., Carroll P.R. Local staging of prostatic carcinoma: comparison of transrectal sonography and endorectal $M R$ imaging. AJR American journal of roentgenology. 1996; 166 (1): 103-8.

4. Wang L., Mullerad M., Chen H.N., Eberhardt S.C., Kattan M.W., Scardino P.T., et al. Prostate cancer: incremental value of endorectal MR imaging findings for prediction of extracapsular extension. Radiology. 2004; 232 (1): 133-9.

5. Xylinas E., Yates D.R., Renard-Penna R., Seringe E., Bousquet J.C., Comperat E., et al. Role of pelvic phased array magnetic resonance imaging in staging of prostate cancer specifically in patients diagnosed with clinically locally advanced ment of the seminal vesicles $[17,18]$ or the rectal wall [19] by GP.

In summary, GP is a rare mimicker of $\mathrm{PCa}$ on multiparametric MRI and it may be very difficult to prospectively differentiate these two entities based on their imaging appearance alone. In the appropriate clinical setting, e.g. a history of prior BCG treatment and discordance of biopsy results and imaging appearance, the reporting radiologist may raise granulomatous inflammation as a possible alternative diagnosis to PCa. However, targeted biopsy and histopathologic analysis is warranted given the relative low prevalence of GP and the very similar imaging features of the two entities.

tumours by digital rectal examination. World journal of urology. 2013; 31 (4): 881-6.

6. Radiology ACo. [Available from: https://www.acr.org/ / media/ACR/Documents/PDF/QualityS afety/Resources/PIRADS/PIRADS-V2.pdf?la=en.

7. Purysko A.S., Rosenkrantz A.B., Barentsz J.O., Weinreb J.C., Macura K.J. PI-RADS Version 2: A Pictorial Update. Radiographics : a review publication of the Radiological Society of North America, Inc. 2016; 36 (5): 1354-72.

8. Hassanzadeh E., Glazer D.I., Dunne R.M., Fennessy F.M., Harisinghani M.G., Tempany C.M. Prostate imaging reporting and data system version 2 (PI-RADS v2): a pictorial review. Abdominal radiology (New York). 2017; 42 (1): 278-89.

9. Kitzing Y.X., Prando A., Varol C., Karczmar G.S., Maclean F., Oto A. Benign Conditions That Mimic Prostate Carcinoma: MR Imaging Features with Histopathologic Correlation. Radiographics : a review publication of the Radiological Society of North America, Inc. 2016; 36 (1): 162-75.

10. Rosenkrantz A.B., Taneja S.S. Radiologist, be aware: ten pitfalls that confound the interpretation of multiparametric prostate MRI. AJR American journal of roentgenology. 2014; 202 (1): 109-20. 


\section{RUSSIAN ELECTRONIC JOURNAL OF RADIOLOGY}

11. Castillo Cadiz O, Villasenin Parrado L, Borgna Christie V, Gallegos Mendez I, Martinez Corta V. Late-onset granulomatous prostatitis following intravesical bacille Calmette-Guerin therapy: case report. Medwave. 2016; 16 (5): e6473.

12. Suzuki T, Takeuchi M, Naiki T, Kawai N, Kohri K, Hara M, et al. MRI findings of granulomatous prostatitis developing after intravesical Bacillus Calmette-Guerin therapy. Clinical radiology. 2013; 68 (6): 595-9.

13. Shukla P, Gulwani HV, Kaur S. Granulomatous prostatitis: clinical and histomorphologic survey of the disease in a tertiary care hospital. Prostate international. 2017; 5 (1): 29-34.

14. Herranz Amo F., Verdu Tartajo F., Diez Cordero J.M., Bueno Chomon G., Leal Hernandez F, Bielsa Carrillo A, et al. [Nonspecific granulomatous prostatitis diagnosed with ultrasonography-guided transrectal biopsy]. Actas urologicas espanolas. 1998; 22 (9): 757-61.

15. Rais-Bahrami S., Nix J.W., Turkbey B., Pietryga J.A., Sanyal R., Thomas J.V., et al. Clinical and multiparametric MRI signatures of granulomatous prostatitis. Abdominal radiology (New
York). 2017.

16. Kawada H., Kanematsu M., Goshima S., Kondo H., Watanabe H., Noda Y., et al. Multiphase contrast-enhanced magnetic resonance imaging features of Bacillus CalmetteGuerin-induced granulomatous prostatitis in five patients. Korean journal of radiology. 2015; 16 (2): 342-8.

17. Dianat S.S., Matoso A., Carter B.H., Macura K.J. Multiparametric MRI findings of granulomatous prostatitis after intravesical bacillus Calmette-Guerin therapy in a patient undergoing active surveillance. Clinical genitourinary cancer. 2014; 12 (5): e215-9.

18. Lee S.M., Joshi J., Wolfe K., Acher P., Liyanage S.H. Radiologic presentation of chronic granulomatous prostatitis mimicking locally advanced prostate adenocarcinoma. Radiology case reports. 2016; 11 (2): 78-82.

19. Xing L., Liu Z., Deng G., Wang H., Zhu Y., Shi P, et al. Xanthogranulomatous prostatitis with prostato-rectal fistula: a case report and review of the literature. Research and reports in urology. 2016; 8: 165-8. 